\title{
Cardiopulmonary stress during exercise training in patients with COPD
}

\author{
V.S. Probst*\#, T. Troosters*,\# , F. Pitta*,\#, M. Decramer*,\# and R. Gosselink*,\#
}

\section{ABSTRACT: Exercise training is an essential component of pulmonary rehabilitation. However, the cardiopulmonary stress imposed during different modalities of exercise training is not yet known.}

In the present study, the cardiopulmonary stress of a 12-week exercise training programme in 11 chronic obstructive pulmonary disease (COPD) patients (forced expiratory volume in one second $42 \pm 12 \%$ pred, age $69 \pm 6$ yrs) was measured. Pulmonary gas exchange and cardiac frequency $(f c)$ of three training sessions were measured with a portable metabolic system at the beginning, mid-term and end of the programme. Symptoms were assessed with Borg scores.

The exercise intensity was compared with the recommendations for exercise training by the American College of Sports Medicine (ACSM). Training effects were significant (maximum change in work: $14 \pm 11$ Watts, 6-min walk test: $44 \pm 36 \mathrm{~m}$ ). Whole body exercises (cycling, walking and stair climbing) consistently resulted in higher cardiopulmonary stress (oxygen uptake $\left(V^{\prime} O_{2}\right)$, minute ventilation and $f c$ ) than arm cranking and resistance training. Dyspnoea was higher during cycling than resistance training. Patients exercised for $>70 \%$ ( $>20 \mathrm{~min}$ ) of the total exercise time at $>40 \%$ of the $V^{\prime} \mathrm{O}_{2}$ reserve and fC reserve ("moderate" intensity according to the ACSM) throughout the programme.

The cardiopulmonary stress resistance training is lower than during whole-body exercise and results in fewer symptoms. In addition, exercise testing based on guidelines using a fixed percentage of baseline peak performance and symptom scores achieves and sustains training intensities recommended according to the American College of Sports Medicine.

KEYWORDS: Chronic obstructive pulmonary disease, exercise training, pulmonary rehabilitation

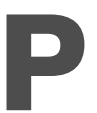

ulmonary rehabilitation (PR) programmes have consistently improved exercise capacity, symptoms and quality of life of patients with chronic obstructive pulmonary disease (COPD). Exercise training is an essential component of PR [1], and endurance training is commonly used. Generally, the endurance type of training applied during PR includes cycling and/or treadmill walking. Programmes including relatively high-intensity endurance training have proven to be effective [1]. However, in addition to walking and cycling, other exercise modalities have been described during PR for COPD patients, e.g. resistance training [2], callisthenics [3], arm cranking [4] and stair climbing [5]. In clinical rehabilitation, a combination of several of these exercises, is often applied. Although it is known that high intensity training leads to more desirable physiological training effects than low intensity training [6], the cardiopulmonary stress imposed by different exercises is not yet known. In addition, training intensity is conventionally set at a given fraction of an incremental peak exercise response. Due to the relatively slow oxygen uptake kinetics of patients with chronic diseases [7, 8], the actual metabolic load during somewhat longer exercise bouts may well be underestimated.

To improve cardiorespiratory fitness, the guidelines for exercise testing and prescription of the American College of Sports Medicine (ACSM) recommend for healthy individuals to exercise three to five times a week at $40-85 \%$ of the maximum oxygen uptake or heart rate reserve for $>20 \mathrm{~min}$ continuously or at intervals [9]. Whether these recommendations are achieved by patients with COPD is debated [1]. It is unknown whether the exercise training regimens applied in the context of PR programmes are sufficient to exercise COPD patients at recommended intensities for healthy individuals. Moreover, the amount of time at which patients train, at given intensities, has not yet been studied.

Therefore, the present authors measured the cardiopulmonarystress of the different components of
AFFILIATIONS

*Respiratory Rehabilitation and Respiratory Division, University Hospitals, and

\#Dept of Rehabilitation Sciences, Faculty of Kinesiology and Rehabilitation Sciences, Katholieke Universiteit Leuven, Leuven, Belgium and

-Dept of Physiotherapy, Universidade Estadual de Londrina, Londrina, Brazil.

CORRESPONDENCE

R. Gosselink

Respiratory Rehabilitation and Respiratory Division University Hospital Gasthuisberg Herestraat 49 B-3000 Leuven

Belgium

Fax: 3216329196

E-mail: rik.gosselink@

faber.kuleuven.be

Received:

September 222005

Accepted after revision:

February 232006

SUPPORT STATEMENT

V.S. Probst is supported by KULeuven/Research Council Scholarships Programme.

T. Troosters is a postdoctoral fellow of the FWO-Vlaanderen. F. Pitta is supported by CAPES/Brasil. Technical support was provided by Viasys, MEDA, Belgium. 
an exercise training programme in the context of pulmonary rehabilitation in patients with moderate-to-severe COPD. In addition, patients were also analysed to determine if they were able to exercise at intensities recommended by the ACSM.

\section{MATERIALS AND METHODS Study subjects}

Eleven consecutive patients visiting the outpatient clinic entered the study. The following criteria were used for patient selection: 1) clinical diagnosis of COPD; 2) stable condition at inclusion with no recent infection or exacerbation; 3 ) remaining symptoms of dyspnoea and reduced exercise capacity despite optimal medical treatment; 4) no locomotor or neurological condition or disability limiting the ability to exercise; 5) no need of supplemental oxygen at rest or during exercise due to the inability of the equipment to measure oxygen uptake $\left(V^{\prime} \mathrm{O}_{2}\right)$ while breathing inspiratory $\mathrm{O}_{2}$ fractions $>21 \%$; and 6) patients had to be able to attend the outpatient rehabilitation centre three times per week. Patients who met the inclusion criteria gave oral informed consent to take part in the study. They performed testing at inclusion and after 3 months of outpatient pulmonary rehabilitation. All tests were part of the routine screening of COPD patients who enter a rehabilitation programme approved by the Medical Ethical Board of the University Hospitals Leuven, Leuven, Belgium. The tests consist of measurement of pulmonary function, peripheral and respiratory muscle strength, exercise capacity and quality of life. Details of all the performed tests have been described before [4].

\section{Maximal exercise capacity}

Maximal exercise capacity was assessed by maximal cycle ergometry. The test was performed on a magnetically braked cycle ergometer (Ergoline 900, Bitz, Germany) according to the standards of the American Thoracic Society/American College of Chest Physicians' statement on Cardiopulmonary Exercise Testing [10]. After 3 min of unloaded pedalling, patients cycled at an incremental work rate $\left(+10 \mathrm{~W} \cdot \mathrm{min}^{-1}\right)$ until exhaustion. Cardiac frequency $(f C)$ was monitored continuously by a $12-$ lead electrocardiogram. Minute ventilation $\left(V^{\prime} \mathrm{E}\right), V^{\prime} \mathrm{O}_{2}$ and carbon dioxide production $\left(V^{\prime} \mathrm{CO}_{2}\right)$ were measured throughout the test. $V^{\prime} \mathrm{O}_{2, \max }$ was referred to predicted values [11]. On-line calculations of breath-by-breath $V^{\prime} \mathrm{E}, V^{\prime} \mathrm{O}_{2}, V^{\prime} \mathrm{CO}_{2}$ and respiratory exchange ratio (RER) were obtained using the VmaxST 1.0 (Viasys, MEDA, Belgium), a portable metabolic system. The device was secured to the upper chest with a harness and, due to its low weight $(650 \mathrm{~g})$, it gave minimal discomfort. The volume measurement was carried out by a turbine (Triple- $\mathrm{V}_{\circledast}$ Sensormedics BV, Bilthoven, the Netherlands). $V^{\prime} \mathrm{O}_{2}$ was analysed using an electrochemical cell, and $V^{\prime} \mathrm{CO}_{2}$ was measured using an infrared analyser. A similar model of this device has been validated by PRIEUR et al. [12]. A face mask (Hans Rudolph Inc., Kansas City, MO, USA) with a dead space of $<30 \mathrm{~mL}$ was carefully adjusted to the patient's face and checked for air leaks.

\section{Training programme}

The 12-week training programme consisted of 1.5-h training sessions, which patients attended three times per week. The circuit training included cycling, walking and leg press resistance training, stair climbing and arm cranking. The training programme was based on previous experience [4] and driven by the patients' perception of their symptoms. Training intensity was set at $60 \%$ of the initial maximal work rate for ergometry cycling, at $75 \%$ of the average walking speed during the 6 -min walk test (6MWT) for treadmill walking and at $70 \%$ of the one repetition maximum (1RM; the maximum load which can be moved only once over the full range of motion without compensatory movements) for leg press resistance training. For walking, the average walking speed was determined by dividing the distance walked by the time (6 min) during the 6MWT performed at admission to the rehabilitation programme. Arm cranking and stair climbing (two-step chair) were performed in 2-min blocks (1-3 sets). Physiotherapists increased patients' work rates or duration on a weekly basis, guided by a schedule and Borg-symptom scores. A Borg score of 4-6 for dyspnoea or fatigue was set as a target [13]. Close supervision was provided during training, with a ratio of one physiotherapist for every four patients. In addition to the exercises, patients also followed education sessions regarding disease management and medication use. There was also individual psychological and social counselling, and nutritional and occupational therapy.

\section{Exercise training session assessments}

By the end of weeks 1, 6 and 12 of the PR programme, patients performed one exercise training session with the VmaxST. Online breath-by-breath measurement of $V^{\prime} \mathrm{E}$, tidal volume $\left(V^{\prime} \mathrm{T}\right)$, $V^{\prime} \mathrm{O}_{2}, V^{\prime} \mathrm{CO}_{2}$, respiratory rate (RR) and the ratio between inspiratory time and total cycle time $\left(t_{i} / t\right.$ tot $)$ were recorded by the VmaxST throughout the training session. $f C$ was assessed using a heart rate monitor (Polar $®$; T31, Kempele, Finland). All variables were recorded at rest (2-min baseline) and during the whole exercise training session, which was identical to the previous clinical rehabilitation session. The session was supervised by a different physiotherapist, who was not involved in the clinical management of the patient. The exercises were performed in a fixed order. After 2 min of unloaded cycling as a warm-up, patients started the loaded cycling, which was followed by leg press resistance training, treadmill walking, arm cranking and finally stair climbing. Sufficient rest was assured after each exercise (patients rested until they felt able to continue). Patients could move freely without discomfort, as the device has a low weight. Pilot data showed that patients were not hindered in their exercise performance by the device [14, 15]. The face mask could be removed during the resting periods between exercises, if necessary.

Patients were asked to grade their symptoms of dyspnoea and fatigue during the exercises using the modified Borg score.

\section{Data handling}

Signals from the VmaxST were transmitted during the training session by telemetry to a portable computer for online inspection of data quality. After the test, stored data were downloaded from the VmaxST to ensure complete breath-bybreath datasets and analysed with computer software.

In order to label the intensity at which patients were exercising, the recommended exercise intensity according to the Guidelines of the ACSM was applied to the cardiopulmonary 
data [10]. The ACSM recommends an intensity of exercise corresponding to $40-85 \%$ of oxygen uptake reserve $\left(V^{\prime} \mathrm{O}_{2}, \mathrm{R}\right)$ or cardiac frequency reserve $(f C, R)$ to increase and maintain cardiorespiratory fitness [16]. The $V^{\prime} \mathrm{O}_{2}, \mathrm{R}$ is calculated from the difference between resting and maximum $V^{\prime} \mathrm{O}_{2}$. Similarly, $f C, \mathrm{R}$ is the difference between resting and maximum $f c$. The thresholds considered as "moderate" and "hard" by the ACSM were used [16]. This means training intensities $>40 \%$ (moderate) and $60 \%$ (hard) of the $V^{\prime} \mathrm{O}_{2}, \mathrm{R}$ and $f C, \mathrm{R}$. To estimate the training intensity moderate and hard, 40 and $60 \%$ of this value, respectively, was added to the resting $V^{\prime} \mathrm{O}_{2}$ and/or resting $f C$ and is expressed as a percentage of $V^{\prime} \mathrm{O}_{2}, \mathrm{R}$ or $f C, R$. A typical formula reads as follows:

$V^{\prime} \mathrm{O}_{2}, \mathrm{R}=V^{\prime} \mathrm{O}_{2}$,rest+0.6 $\left(V^{\prime} \mathrm{O}_{2}, \max -V^{\prime} \mathrm{O}_{2}\right.$,rest $)$

\section{Statistical analysis}

Data were checked for normal distribution with the Kolmogorov-Smirnov test. The effects of exercise training were analysed with paired t-test. The cardiopulmonary measurements assessed in weeks 1, 6 and 12 were analysed with the repeated-measures ANOVA. If a p-value was $<0.05$, Tukey's post test was performed. For the symptom scores, the comparison was carried out with the Friedman test. In this case, if a p-value was $<0.05$, the Dunn's post test was performed. The level of significance for all comparisons was set at $\mathrm{p}<0.05$.

\section{RESULTS}

The studied group (table 1) showed moderate-to-severe airflow obstruction and was classified within Global Initiative for Chronic Obstructive Lung Disease stages II $(n=4)$, III $(n=4)$ and IV $(n=3)$. One patient had an acute exacerbation and could not be reassessed at week 6 . Another patient withdrew from the rehabilitation programme at week 12 for personal reasons and could not perform the final exercise training session with the VmaxST. However, all the other measurements after 12 weeks were successfully performed by this patient. Although the assessments with the VmaxST throughout the exercise training sessions were well tolerated by patients, in week 12 two patients reported difficulties exercising while wearing the equipment ( $6 \%$ of measurements).

\section{Training effect}

As expected, FEV1 remained unaltered after 12 weeks of exercise training $(\Delta \mathrm{FEV} 1=0.02 \pm 0.18 \mathrm{~L} ; \mathrm{p}=0.41) . \quad V^{\prime} \mathrm{O}_{2}, \max$, $W_{\max }$ and 6MWT increased significantly after training $\left(0.09 \pm 0.13 \mathrm{~L} \cdot \mathrm{min}^{-1}, 14 \pm 11 \mathrm{~W}\right.$ and $44 \pm 36 \mathrm{~m}$, respectively; $\mathrm{p}<0.05$ for all). There was no statistically significant difference in isometric quadriceps force $\left(\Delta \mathrm{QF}=5 \pm 16 \mathrm{~N} \cdot \mathrm{m}^{-1} ; \mathrm{p}=0.25\right)$, despite a significant increase of the training load of the leg press resistance training during the programme $(\Delta \mathrm{load}=53 \pm 30 \mathrm{~kg} ; \mathrm{p}=0.0001$, which represents $43 \pm 26 \%$ increase). $V^{\prime} \mathrm{O}_{2}, V^{\prime} \mathrm{CO}_{2}, V^{\prime} \mathrm{E}$ and $f \mathrm{C}$ at iso-work rate $(100 \%$ of the initial maximal work rate) decreased significantly after 12 weeks of exercise training (reductions of $7,15,9$ and $7 \%$, respectively; $\mathrm{p}<0.02$ for all).

\section{Cardiopulmonary response and symptoms during the exercise training programme}

Figure 1 shows the progression of the training load for cycling, leg press resistance training and walking during the exercise training programme. There were patients who sustained high intensity training from the first week on and were able to tolerate further increments in the exercise load during the programme. However, others improved their training load less than predicted (fig. 1). Participation rate was $97 \%$.

There was no difference in heart rate before starting a given exercise in weeks 1,6 and $12(\mathrm{p}=0.39,0.60$ and 0.36, respectively).

There was an overall increase in $V^{\prime} \mathrm{O}_{2}, V^{\prime} \mathrm{E}$ and $f \mathrm{C}$ during leg press and arm cranking throughout the 12-week programme ( $\mathrm{p}<0.05$ for both). $V^{\prime} \mathrm{E}$ during stair climbing was also higher in week $12(\mathrm{p}=0.02)$. For the remaining exercises, despite significant increase in work rate, $V^{\prime} \mathrm{O}_{2}, V^{\prime} \mathrm{E}$ and $f \mathrm{C}$ remained unchanged over time. Symptoms reported during exercises did not change throughout the programme, except for an increased dyspnoea during arm cranking $(\mathrm{p}<0.05)$ and an increase in fatigue during walking $(\mathrm{p}=0.02)$ at the end of the programme.

$V^{\prime} \mathrm{O}_{2}, V^{\prime} \mathrm{E}$ and $f C$ responses of a representative patient during a training session in week 1 are illustrated in figure 2 . This patient (male, $51 \mathrm{~kg}$, FEV1 $0.88 \mathrm{~L}$ ) cycled at $55 \mathrm{~W}$ (69\% Wmax) for $10 \mathrm{~min}$, performed leg press resistance training (three sets of eight repetitions) with $110 \mathrm{~kg}(70 \% 1 \mathrm{RM})$, walked on the treadmill with a speed of $4.2 \mathrm{~km} \cdot \mathrm{h}^{-1}$ (74\% 6MWTspeed) for $10 \mathrm{~min}$, and performed arm cranking and stair climbing, each for $2 \mathrm{~min}$. The values of $V^{\prime} \mathrm{O}_{2}, V^{\prime} \mathrm{E}$ and $f \mathrm{C}$ achieved at the end of the different exercises by this patient were close to the maximal values obtained during the initial incremental exercise test.

The average cardiopulmonary stress imposed by the different exercise modalities throughout the training programme is shown in table 2. Relatively high intensity exercise in terms of $V^{\prime} \mathrm{O}_{2}, V^{\prime} \mathrm{E}$ and $f C$ was reached from the first week on. The cardiopulmonary responses were lower during arm exercises (arm cranking) and resistance training (leg press) when compared with whole body exercises (cycling, walking and stair climbing; table 2). Similarly to $V^{\prime} \mathrm{O}_{2}, V^{\prime} \mathrm{E}$ and $f C$, symptoms of dyspnoea reported by patients were consistently lower during leg press when compared to cycling ( $\mathrm{p}<0.05$ week 1,6 and 12). In terms of fatigue sensation, leg press induced less fatigue than cycling at week $12(\mathrm{p}<0.01)$.

The ventilatory equivalent for oxygen $\left(V^{\prime} \mathrm{E} / V^{\prime} \mathrm{O}_{2}\right)$ was systematically lower during walking when compared to cycling during the programme $(\mathrm{p}<0.001)$. Note that $V^{\prime} \mathrm{O}_{2}$ was not different between these two exercises. The RER was also higher during cycling when compared with walking in weeks 1 and $12(\mathrm{p}<0.0001)$.

\section{Exercise time and thresholds of exercise intensity}

The duration of the trainings increased over time and were $66 \pm 7,81 \pm 7$ and $80 \pm 13 \mathrm{~min}$ in weeks 1,6 and 12 , respectively (ANOVA, $\mathrm{p}=0.02$ ). The corresponding exercise time was $30 \pm 3 \mathrm{~min}$ in week $1,38 \pm 4 \mathrm{~min}$ in week 6 and $36 \pm 10 \mathrm{~min}$ in week 12 (ANOVA, $\mathrm{p}=0.03$ ). This represents 46,47 and $45 \%$ (weeks 1, 6 and 12, respectively) of the training session.

Figure 3 shows the total exercise time as well as the time above the thresholds considered moderate and hard $(\geqslant 40$ and $\geqslant 60 \%$ of $V^{\prime} \mathrm{O}_{2}, \mathrm{R}$ and $f C, \mathrm{R}$, respectively) by the ACSM in weeks 1,6 and 12. Patients spent $>80 \%$ of the total exercise time above $40 \%$ of $V^{\prime} \mathrm{O}_{2}, \mathrm{R}$ (moderate threshold; $88 \pm 7,89 \pm 7$ and $84 \pm 9 \%$ in weeks 


\section{TABLE 1 Baseline characteristics.}

\begin{tabular}{|c|c|}
\hline Sex M/F & $10 / 1$ \\
\hline Age yrs & $69 \pm 6$ \\
\hline BMI $\mathbf{k g} \cdot \mathrm{m}^{-2}$ & $27 \pm 7$ \\
\hline FEV $1 \%$ pred & $42 \pm 12$ \\
\hline TL,co \%pred & $59 \pm 19$ \\
\hline $6 \mathrm{MWT} \%$ pred & $74 \pm 18$ \\
\hline QF \% pred & $74 \pm 11$ \\
\hline$W_{\max } \%$ pred & $54 \pm 17$ \\
\hline$V^{\prime} \mathrm{O}_{2}$,max \% pred & $64 \pm 33$ \\
\hline$V^{\prime} E, \max \% M V V$ & $92 \pm 26$ \\
\hline$f C, \max \%$ pred & $79 \pm 15$ \\
\hline
\end{tabular}

Data are presented as mean \pm SD. M: male; F: female; BMI: body mass index; FEV1: forced expiratory volume in one second; TL,Co: diffusion capacity for carbon monoxide; 6MWT: 6-min walk test; QF: quadriceps force; Wmax: baseline maximal workload; $V^{\prime} \mathrm{O}_{2}$ max: baseline maximum oxygen uptake; $V^{\prime} E$,max: baseline maximum minute ventilation; MVV: maximal voluntary ventilation; $f \mathrm{C}$,max: baseline maximum heart rate.

1, 6 and 12, respectively; ANOVA, $\mathrm{p}=0.18$ ). Concerning the $f C, R$, patients achieved moderate intensities for $>70 \%$ of the total exercise time $(76 \pm 29,71 \pm 22$ and $83 \pm 23 \%$ in weeks 1,6 and 12 , respectively; $p=0.36$; fig. $3 a)$. For the threshold considered hard $\left(\geqslant 60 \%\right.$ of $V^{\prime} \mathrm{O}_{2}, \mathrm{R}$ or $\left.f C, \mathrm{R}\right)$, patients spent $67 \pm 25 \%$ of the total exercise time above this intensity in terms of $V^{\prime} \mathrm{O}_{2}, \mathrm{R}$ in week 1 and $75 \pm 15 \%$ in weeks 6 and 12 (ANOVA, $\mathrm{p}=0.33$ ). Slightly less time was spent above the intensity hard in terms of $f C, R ; 51 \pm 42 \%$ in week $1,48 \pm 30 \%$ in week 6 and $64 \pm 34 \%$ in week 12 ; ANOVA, $p=0.26$; fig. $3 b$ ).

There was poor agreement between the thresholds based on the $V^{\prime} \mathrm{O}_{2}, \mathrm{R}$ in comparison to those based on the $f C, \mathrm{R}$ throughout the programme. An example of this lack of concordance between these two thresholds of exercise intensity is shown in fig. 4.

\section{DISCUSSION}

The present study showed that the applied exercise training programme enabled the studied group to achieve and sustain training intensities that are well within the limits of what is proposed to be effective for healthy adults according to the ACSM. In addition, resistance training (leg press) resulted in less cardiopulmonary stress when compared with whole body exercises. Lastly, a poor concordance between intensity based on $V^{\prime} \mathrm{O}_{2}, \mathrm{R}$ and heart rate reserve was shown, i.e. an acceptable training intensity in terms of $V^{\prime} \mathrm{O}_{2}, \mathrm{R}$ was reached at a heart rate which would be considered too low.

\section{Work rate progression and whole body exercises}

Although guidelines were given for work rate progression, this progress was variable among patients due to symptoms (fig. 1). The work rate progress patients presented during the training may partially have been the result of an improvement in movement efficiency, as a relatively larger increase was observed in training load (intensity and duration) than in $V^{\prime} \mathrm{O}_{2}$. MILANI et al. [17] have previously shown that COPD patients improve mechanical efficiency to a larger extent than $V^{\prime} \mathrm{O}_{2}$ after exercise training.

For most of the patients, the intensity achieved during cycling, walking and stair climbing was high enough to produce oxygen consumption and ventilation close to maximal responses achieved in the baseline incremental cycling. Although the three whole-body activities (cycling, walking and stair climbing) resulted in similar cardiopulmonary responses, they have different characteristics and were performed in different ways. During cycling, most of the patients performed interval training (5-8 sets of 2-min blocks). This is a common approach to be able to train at relatively high work rates. Others have shown that COPD patients achieve higher work rates during interval training when compared with continuous training [18]. During treadmill walking, most of the patients tolerated longer blocks of continuous exercise, even with increments in walking speed and duration. This is probably due to the differences between these two exercise modalities. In comparison with cycling, walking has been shown to be less fatiguing and to produce less lactate at similar $V^{\prime} \mathrm{O}_{2}$ levels [19-21]. Hence, patients are able to exercise for longer periods. During cycling, more lactate is produced,
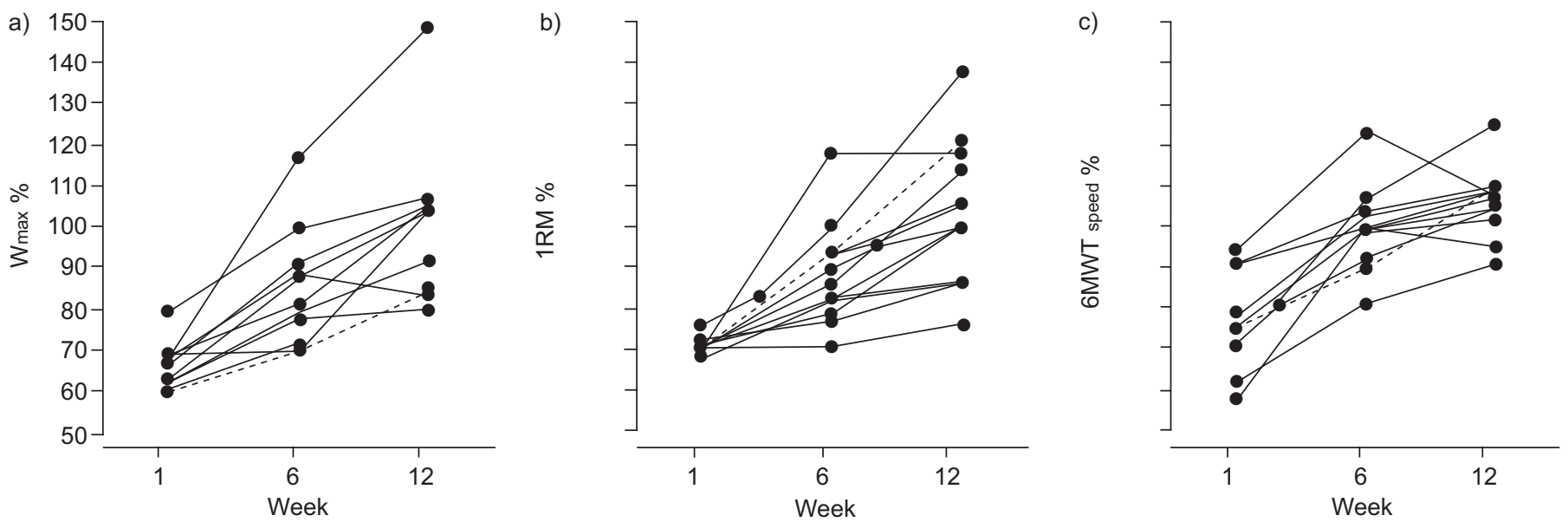

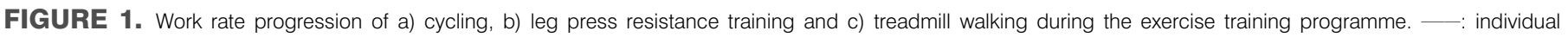

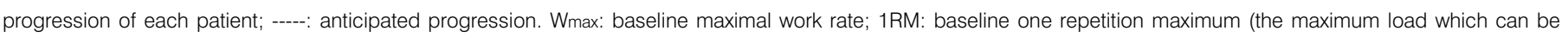
moved only once over the full range of motion without compensatory movements); 6MWT: baseline 6-min walk test. 

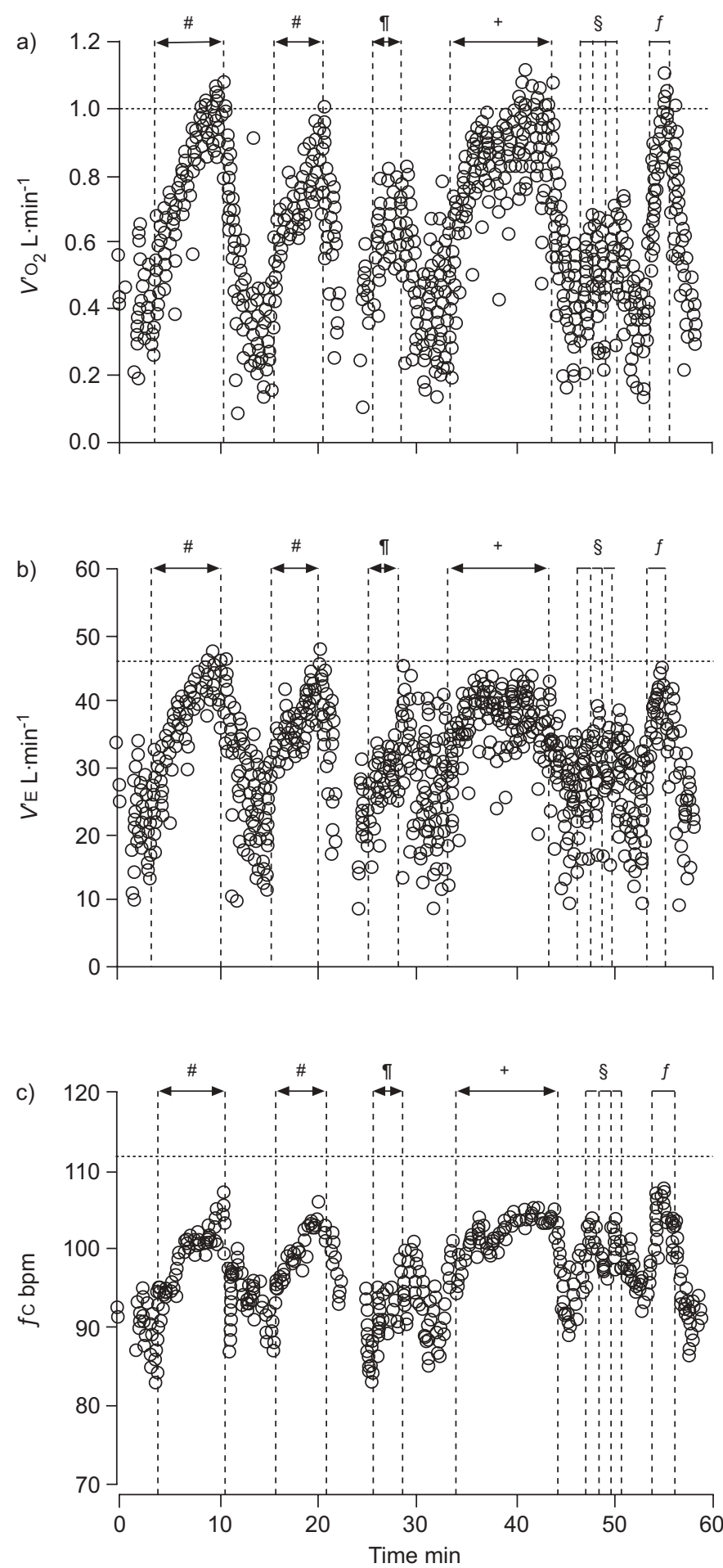

FIGURE 2. a) Oxygen uptake $\left(V^{\prime} \mathrm{O}_{2}\right)$, b) minute ventilation $\left(V^{\prime} \mathrm{E}\right)$, and c) cardiac frequency $(f C)$ in a representative patient during one exercise session in week 1. ----: $V^{\prime} \mathrm{O}_{2}, \max (\mathrm{a}), V^{\prime} E$, max (b) and HRmax (c) achieved during baseline incremental exercise in this patient. ${ }^{\#}$ : cycling; ": leg press resistance; ${ }^{+}$: treadmill walking; ${ }^{\text {s: }}$ arm cranking; $f$ : stair climbing

which results in a continuous rise in ventilation (the so-called slow phase of ventilatory rise at iso-load) [20]. In order to cope with the increasing ventilatory stress, the exercise blocks (especially during cycling) were divided into shorter blocks.
Although lactate was not measured in the present study, the higher RER and $V^{\prime} \mathrm{E} / V^{\prime} \mathrm{O}_{2}$ during cycling compared with walking are suggestive of more lactate production. In addition, other differences during cycling and walking, such as more hypoxaemia [21,22] and increased dead space [21], may also have influenced the performance of these exercises.

During stair climbing, patients also stepped in short blocks (13 sets of 2-min blocks). This activity resulted in similar levels of $V^{\prime} \mathrm{O}_{2}, V^{\prime} \mathrm{E}, f \mathrm{C}$ and symptoms to cycling and walking. The profile of stair climbing is, however, different, as patients reach peak exercise responses very quickly. Therefore, it is difficult, if not impossible, to sustain this activity for longer periods with the current applied pace $\left(\sim 22 \mathrm{steps} \cdot \mathrm{min}^{-1}\right)$ and step height $(21 \mathrm{~cm})$. The fixed order of the exercises, with stair climbing being the last one, could potentially have led to a gradual increase in the cardiopulmonary stress and may have increased kinetics of the cardiopulmonary adaptation [23]. However, patients were able to rest for long periods before starting a given exercise, which allowed heart rate to decrease sufficiently after each activity. Furthermore, others have shown the high cardiopulmonary stress imposed by stair climbing. Previous studies have shown that in patients with chronic airflow obstruction [24] and chronic heart failure [25], stair climbing represents strenuous exercise, eliciting physiological responses similar to cycle ergometry and treadmill tests.

\section{Arm exercise and resistance training}

The cardiopulmonary stress imposed by arm exercise and resistance training was lower when compared with whole body exercises (cycling, walking and stair climbing). CARTER et al. [26] found reduced work capacity for arms compared with legs in COPD patients. This is a consequence of the smaller muscle mass involved during arm exercises. However, although the cardiopulmonary response was lower during arm cranking in comparison with cycling, there was no difference in symptoms of dyspnoea. This may be due to the features of the pulmonary disease which may also hinder the performance of arm work, such as dyssynchronous breathing [27], involvement of inspiratory muscles of the rib cage in upper torso and arm positioning [28], nutritional status [29] and dynamic hyperinflation [30].

For leg press resistance training, in addition to the lower cardiopulmonary stress, patients also experienced less dyspnoea in comparison to cycling. RICHARDSON et al. [31] showed that exercising the quadriceps muscle alone (knee extensor exercise) resulted in lower peak values of $V^{\prime} \mathrm{O}_{2}, V^{\prime} \mathrm{E}$ and $f C$ and fewer symptoms of dyspnoea when compared with cycling. In addition, the lower cardiopulmonary stress achieved during leg press can also be attributed to the average duration of this exercise. The exercise time for leg press was $2 \mathrm{~min}$ throughout the training (three sets of eight repetitions), which may also have contributed to the lower cardiopulmonary response The reduced sensation of dyspnoea during leg press is not surprising, since, during resistance training, patients are not usually limited by the central cardiorespiratory limitations commonly present in COPD. This will result in fewer symptoms, and consequently, patients are able to achieve significantly higher relative work rates [31, 32]. Although patients presented an increase in load during quadriceps 


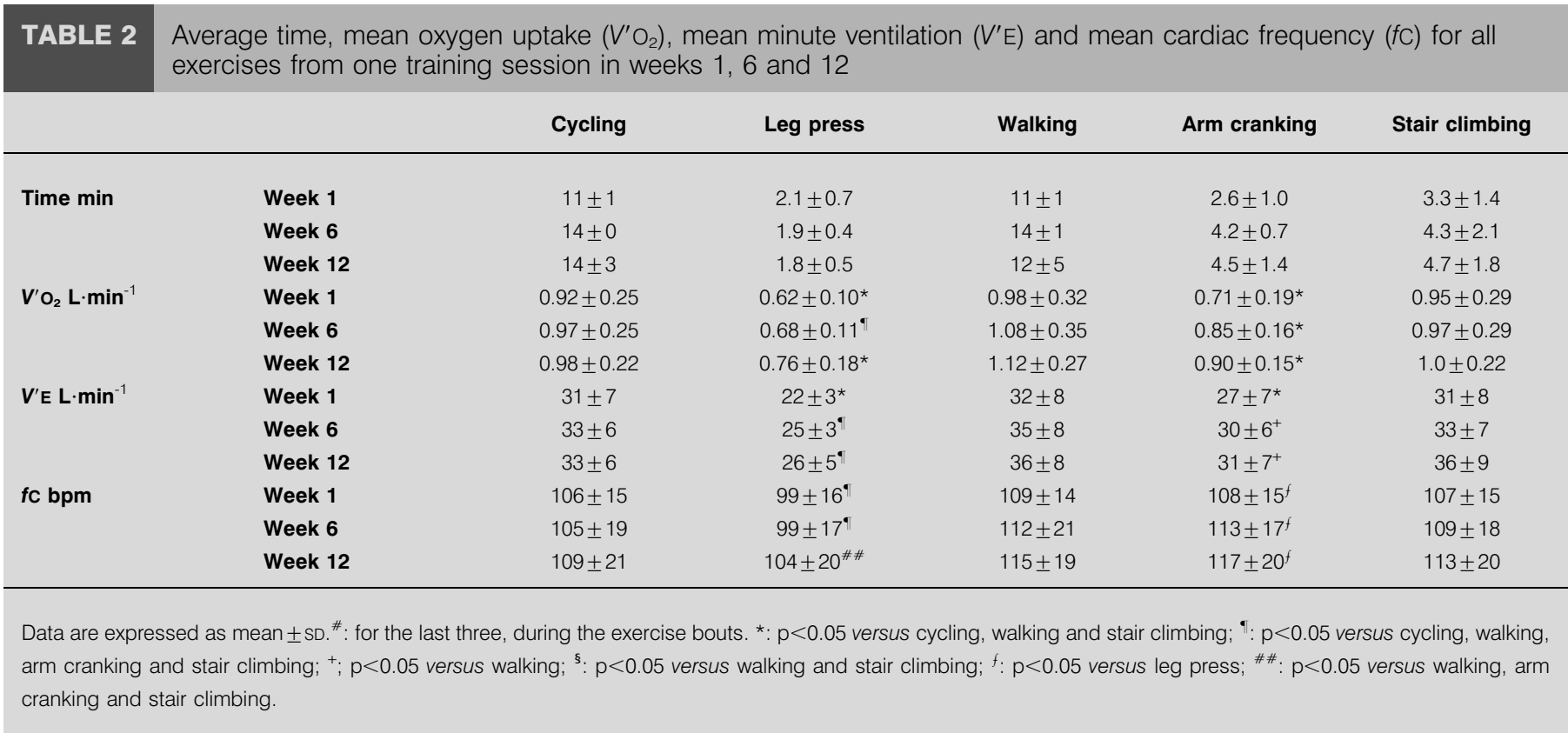

resistance training, this progression was lower than what was anticipated based on experience in healthy elderly [33, 34]. However, the load progression observed in the present study was similar to that achieved in other studies, including COPD patients, which showed a significant effect on lower limb muscle force $[2,5]$.

\section{Exercise time and thresholds of exercise intensity}

In the present study, patients spent less than half of the total time of the training session executing the prescribed exercises. This was due to the characteristics of most of the exercises performed (intermittent) and the relatively long periods of rest patients needed in order to recover after each exercise. Intermittent exercise has been shown to be time consuming [35]. In addition, LACASSE et al. [36] showed that COPD patients have a lower heart rate recovery after exercise when compared with healthy subjects, requiring longer rest periods.

There was a higher variability in exercise time in week 12 . This was probably due to the fact that two patients could not perform the exercises as planned because of complaints such as dyspnoea on the day of the assessment.

The thresholds of exercise intensity achieved in the present study are those proposed by the ACSM to improve cardiorespiratory fitness. Exercises should be performed between three and five times a week for $>20 \mathrm{~min}$ (or, at lower intensity, preferably $30 \mathrm{~min}$ ), either continuously or in intervals, at an intensity of $40-85 \%$ of the $V^{\prime} \mathrm{O}_{2}, \mathrm{R}$ or $f C, \mathrm{R}$ [9]. In the present study, patients succeeded in achieving these thresholds, as they exercised three times a week at $>40 \%$ of the $V^{\prime} \mathrm{O}_{2}, \mathrm{R}$ (which
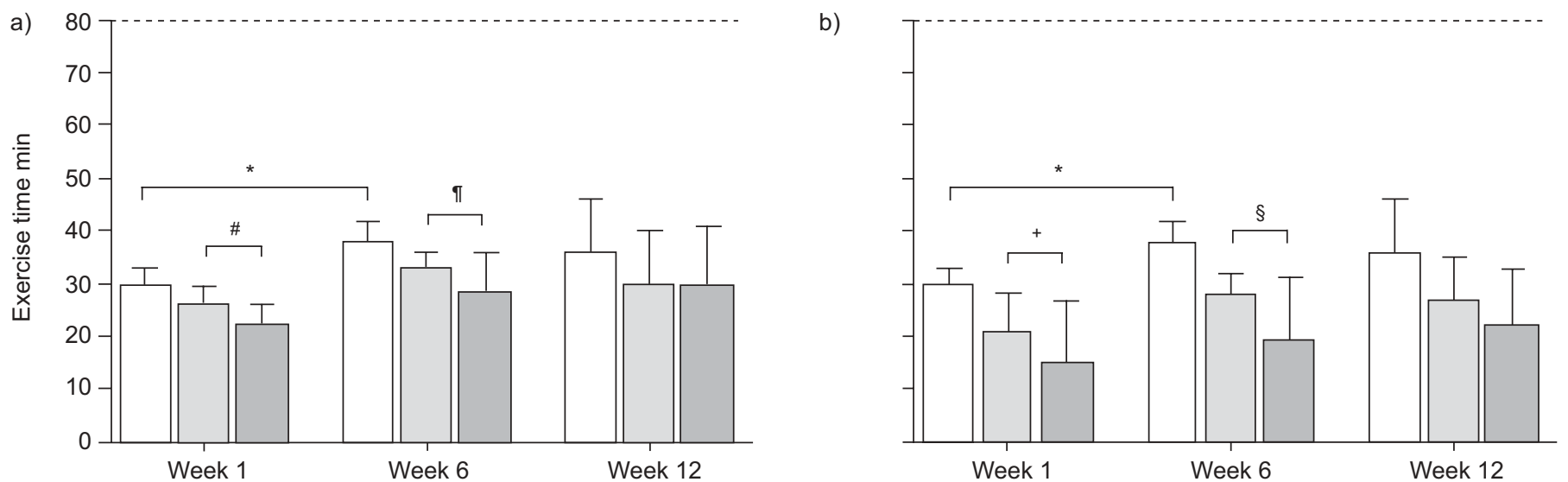

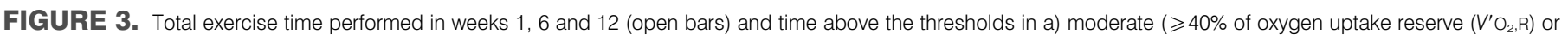

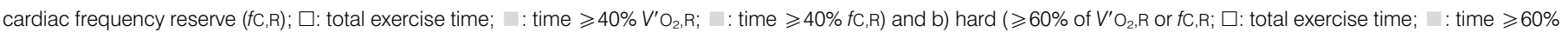

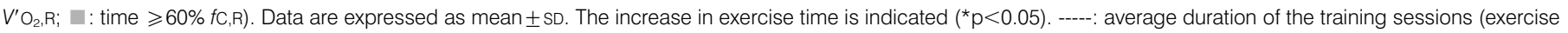
time+resting time). ${ }^{*}: p=0.12 ;{ }^{\bullet}: p=0.11 ;{ }^{+}: p=0.059 ;{ }^{\S}: p=0.054$. 


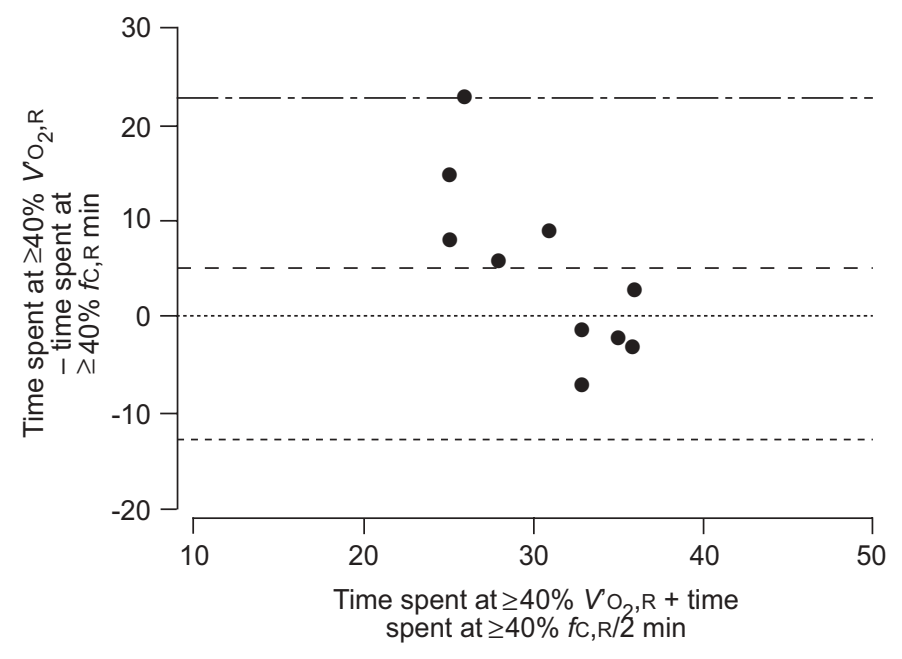

FIGURE 4. Bland and Altman plot showing the poor agreement between time spent in exercises $>40 \%$ of the oxygen uptake reserve $\left(V^{\prime} \mathrm{O}_{2}, \mathrm{R}\right)$ and $>40 \%$ of the cardiac frequency reserve $(\mathrm{fC}, \mathrm{R})$. -.-_-_--•: upper limit $($ mean+(1.96 $\times \mathrm{SD}))$; ------: lower limit (mean-(1.96 $\times \mathrm{SD}))$; - - - -: mean.

corresponded to $55 \%$ of baseline $V^{\prime} \mathrm{O}_{2}, \max$ ) and $f C, \mathrm{R}$ (corresponding to $84 \%$ of baseline $f C$, $\max$ ) for $>20 \mathrm{~min}$ (considered as moderate intensity by the ACSM). When higher intensities were set ( $\geqslant 60 \%$ of the $V^{\prime} \mathrm{O}_{2}, \mathrm{R}$ and $f C R$; $A C S H^{\prime}$ s hard intensity), it was observed that the time period during which patients were exercising at such intensities was lower. However, patients still remained $>20 \mathrm{~min}$ above the threshold hard for $V^{\prime} \mathrm{O}_{2}, \mathrm{R}$ (corresponding to $70 \%$ of baseline $V^{\prime} \mathrm{O}_{2}$, max). In terms of $f C, R$, patients only exercised at $\geqslant 60 \%$ of the $f C, R$ (which corresponded to $89 \%$ of baseline $f(\mathrm{C}, \max$ ) for $>20 \mathrm{~min}$ in week 12. In the present study, training intensities target following published guidelines and symptoms resulted in a homogeneous response of thresholds based on $V^{\prime} \mathrm{O}_{2}$. Much more variable, however, was the response based on $f C$. The poor agreement between time spent above the thresholds based on $V^{\prime} \mathrm{O}_{2}$ and $f C$ may be related to different factors. The differences between the $f C$ and $V^{\prime} \mathrm{O}_{2}$ kinetics might be one of the factors. It has been shown in COPD that $f C$ kinetics are slower when compared with $V^{\prime} \mathrm{O}_{2}$ kinetics during exercise [8]. In addition, ventilatory limitation to exercise is often present in patients with COPD. Consequently, it is common that patients stop exercising before reaching their cardiocirculatory limits [37]. These features indicate that heart rate may not be an appropriate target to set exercise intensity to COPD patients; this has been previously suggested by others [38].

\section{Limitations of the study}

Patients who needed oxygen supplementation could not be included in the study. This was due to the inability of the VmaxST equipment to measure $V^{\prime} \mathrm{O}_{2}$ while breathing inspiratory $\mathrm{O}_{2}$ fractions $>21 \%$ (room air). Therefore, the present results may not be readily extrapolated to the more severe patients. However, since leg press resistance training elicited less $V^{\prime} \mathrm{E}$ and dyspnoea than whole body exercise in the present study, it might be expected that the more severe patients may especially benefit from this type of exercise. These patients usually have dynamic hyperinflation [30] and ventilatory limitations are more apparent, hence, small muscle group training may be especially interesting in this population.

The present study does not allow identification of the minimal training intensity at which COPD patients should exercise in order to achieve physiological training effects. Rather, the cardiopulmonary stress imposed was investigated during clinical rehabilitation at a given fraction of the peak work rate.

The small sample size could be considered a limitation, since it may hinder the generalisation of the results. Specifically, severely oxygen-dependent COPD patients were not included in the present study. In addition, although the exercise training applied to the COPD patients is rather similar among centres, there might be differences in the programmes which may result in different cardiopulmonary stress. Nevertheless, the present data strongly support the relatively high cardiopulmonary stress of whole body exercise training in COPD.

In summary, the results of the present study provide new insights into training intensity imposed on chronic obstructive pulmonary disease patients with conventional exercise training programmes, since the majority of the patients trained at relatively high work rates. Without knowing the results of the metabolic assessments during the training, physiotherapists were able to keep patients at high intensity training based on guidelines using a fixed percentage of baseline peak performance further guided by symptoms scores. The patients with moderate-to-severe airflow obstruction included in the study tolerated relatively high intensity training and obtained significant improvements in exercise capacity after completion of the programme. The cardiopulmonary stress during resistance training is, as expected, lower than during wholebody exercise and results in fewer symptoms. The applied exercise training programme enabled the studied group to achieve and sustain training intensities that are recommended according to the American College of Sports Medicine. Exercise training based on guidelines using a fixed percentage of baseline peak performance and symptom scores seems to result in relatively homogeneous oxygen uptake response, while cardiac frequency response is much more variable. This would not incite for the use of cardiac frequency to guide training intensity in chronic obstructive pulmonary disease.

\section{ACKNOWLEDGEMENTS}

The authors would like to thank the following for the fundamental help in the assessments: I. Coosemans, V. Barbier, I. Muyllaert, A. Debrock, M. van Vliet, G. Maury, E. Libaert, L. Vandromme and the Lung Function staff of the Respiratory Dept from UZ Gasthuisberg, Leuven, Belgium.

\section{REFERENCES}

1 Troosters T, Casaburi R, Gosselink R, Decramer $M$. Pulmonary rehabilitation in chronic obstructive pulmonary disease. Am J Respir Crit Care Med 2005; 172: 19-38.

2 Ortega F, Toral J, Cejudo P, et al. Comparison of effects of strength and endurance training in patients with chronic obstructive pulmonary disease. Am J Respir Crit Care Med 2002; 166: 669-674.

3 Normandin EA, McCusker C, Connors M, Vale F, Gerardi D, ZuWallack RL. An evaluation of two 
approaches to exercise conditioning in pulmonary rehabilitation. Chest 2002; 121: 1085-1091.

4 Troosters T, Gosselink R, Decramer M. Short and long term effects of outpatient rehabilitation in patients with chronic obstructive pulmonary disease: a randomized trial. Am J Med 2000; 109: 207-212.

5 Spruit MA, Gosselink R, Troosters T, De Paepe K, Decramer M. Resistance versus endurance training in patients with COPD and peripheral muscle weakness. Eur Respir J 2002; 19: 1072-1078.

6 Puente-Maestu L, Sanz ML, Sanz P, et al. Effects of two types of training on pulmonary and cardiac responses to moderate exercise in patients with COPD. Eur Respir J 2000; 15: 1026-1032.

7 Neder JA, Jones PW, Nery LE, Whipp BJ. Determinants of the exercise endurance capacity in patients with chronic obstructive pulmonary disease. The power-duration relationship. Am J Respir Crit Care Med 2000; 162: 497-504.

8 Puente-Maestu L, Sanz ML, Sanz P, Nunez A, Gonzalez F, Whipp BJ. Reproducibility of the parameters of the ontransient cardiopulmonary responses during moderate exercise in patients with chronic obstructive pulmonary disease. Eur J Appl Physiol 2001; 85: 434-441.

9 American College of Sports Medicine Position Stand, The recommended quantity and quality of exercise for developing and maintaining cardiorespiratory and muscular fitness in healthy adults. Med Sci Sports Exerc 1998; 30: 975-991.

10 American Thoracic Society/American College of Chest Physicians. ATS/ACCP Statement on cardiopulmonary exercise testing. Am J Respir Crit Care Med 2003; 167: 211-277.

11 Jones NL, Makrides L, Hitchcock C, Chypchar T, McCartney N. Normal standards for an incremental progressive cycle ergometer test. Am Rev Respir Dis 1985; 131: 700-708.

12 Prieur F, Castells J, Denis C. A methodology to assess the accuracy of a portable metabolic system (VmaxST). Med Sci Sports Exerc 2003; 35: 879-885.

13 Horowitz MB, Littenberg B, Mahler DA. Dyspnea ratings for prescribing exercise intensity in patients with COPD. Chest 1996; 109: 1169-1175.

14 Probst VS, Troosters T, Coosemans I, et al. Mechanisms of improvement in exercise capacity using a rollator in patients with COPD. Chest 2004; 126: 1102-1107.

15 Probst VS, Troosters T, Pitta F, et al. Metabolic stress during exercise training in COPD. Proc Am Thorac Soc (Abstr) 2005; 2: A315.

16 American College of Sports Medicine. Guidelines for Exercise Testing and Prescription. Indianapolis, IN, American College of Sports Medicine, 2005.

17 Milani RV, Lavie CJ. Disparate effects of out-patient cardiac and pulmonary rehabilitation programs on work efficiency and peak aerobic capacity in patients with coronary disease or severe obstructive pulmonary disease. J Cardiopulm Rehabil 1998; 18: 17-22.

18 Vogiatzis I, Nanas S, Roussos C. Interval training as an alternative modality to continuous exercise in patients with COPD. Eur Respir J 2002; 20: 12-19.

19 Pepin V, Saey D, Whittom F, LeBlanc P, Maltais F. Walking versus cycling: sensitivity to bronchodilation in chronic obstructive pulmonary disease. Am J Respir Crit Care Med 2005; 172: 1517-1522.

20 Troosters T, Vilaro J, Rabinovich R, et al. Physiological responses to the 6-min walk test in patients with chronic obstructive pulmonary disease. Eur Respir J 2002; 20: 564-569.

21 Palange $P$, Forte $S$, Onorati $P$, Manfredi F, Serra $P$, Carlone $\mathrm{S}$. Ventilatory and metabolic adaptations to walking and cycling in patients with COPD. J Appl Physiol 2000; 88: 1715-1720.

22 Christensen CC, Ryg MS, Edvardsen A, Skjonsberg $\mathrm{OH}$. Effect of exercise mode on oxygen uptake and blood gases in COPD patients. Respir Med 2004; 98: 656-660.

23 Gerbino A, Ward SA, Whipp BJ. Effects of prior exercise on pulmonary gas-exchange kinetics during high-intensity exercise in humans. J Appl Physiol 1996; 80: 99-107.

24 Pollock M, Roa J, Benditt J, Celli B. Estimation of ventilatory reserve by stair climbing. A study in patients with chronic airflow obstruction. Chest 1993; 104: 1378-1383.

25 Reddy HK, McElroy PA, Janicki JS, Weber KT. Response in oxygen uptake and ventilation during stair climbing in patients with chronic heart failure. Am J Cardiol 1989; 63: 222-225.

26 Carter R, Holiday DB, Stocks J, Tiep B. Peak physiologic responses to arm and leg ergometry in male and female patients with airflow obstruction. Chest 2003; 124: 511-518.

27 Celli BR, Rassulo J, Make BJ. Dyssynchronous breathing during arm but not leg exercise in patients with chronic airflow obstruction. N Engl J Med 1986; 314: 1485-1490.

28 Celli B, Criner G, Rassulo J. Ventilatory muscle recruitment during unsupported arm exercise in normal subjects. $J$ Appl Physiol 1988; 64: 1936-1941.

29 Schols AM, Slangen J, Volovics L, Wouters EF. Weight loss is a reversible factor in the prognosis of chronic obstructive pulmonary disease. Am J Respir Crit Care Med 1998; 157: 1791-1797.

30 Epstein SK, Celli BR, Williams J, Tarpy S, Roa J, Shannon T. Ventilatory response to arm elevation. Its determinants and use in patients with chronic obstructive pulmonary disease. Am J Respir Crit Care Med 1995; 152: 211-216.

31 Richardson RS, Sheldon J, Poole DC, Hopkins SR, Ries AL, Wagner PD. Evidence of skeletal muscle metabolic reserve during whole body exercise in patients with chronic obstructive pulmonary disease. Am J Respir Crit Care Med 1999; 159: 881-885.

32 Richardson RS, Leek BT, Gavin TP, et al. Reduced mechanical efficiency in chronic obstructive pulmonary disease but normal peak $\mathrm{VO}_{2}$ with small muscle mass exercise. Am J Respir Crit Care Med 2004; 169: 89-96.

33 Frontera WR, Meredith CN, O'Reilly KP, Knuttgen HG, Evans WJ. Strength conditioning in older men: skeletal muscle hypertrophy and improved function. J Appl Physiol 1988; 64: 1038-1044.

34 Evans WJ. Exercise training guidelines for the elderly. Med Sci Sports Exerc 1999; 31: 12-17.

35 Sabapathy S, Kingsley RA, Schneider DA, Adams L, Morris NR. Continuous and intermittent exercise 
responses in individuals with chronic obstructive pulmonary disease. Thorax 2004; 59: 1026-1031.

36 Lacasse M, Maltais F, Poirier P, et al. Post-exercise heart rate recovery and mortality in chronic obstructive pulmonary disease. Respir Med 2005; 99: 877-886.

37 Plankeel JF, McMullen B, MacIntyre NR. Exercise outcomes after pulmonary rehabilitation depend on the initial mechanism of exercise limitation among nonoxygen-dependent COPD patients. Chest 2005; 127: 110-116.

38 Brolin SE, Cecins NM, Jenkins SC. Questioning the use of heart rate and dyspnea in the prescription of exercise in subjects with chronic obstructive pulmonary disease. $J$ Cardiopulm Rehabil 2003; 23: 228-234. 